\section{A prospective evaluation of posterior capsule opacification in eyes with diabetes mellitus: a case-control study}

MR Praveen ${ }^{1}$, AR Vasavada 1 , GD Shah¹, AR Shah', BM Khamar ${ }^{2}$ and KH Dave ${ }^{1}$
${ }^{1}$ lladevi Cataract and IOL Research Center, Raghudeep Eye Clinic, Ahmedabad, India

${ }^{2}$ Retina Clinic, Thakore Eye Hospital, Ahmedabad, India

Correspondence: AR Vasavada, Iladevi Cataract and IOL Research Center, Raghudeep Eye Clinic, Gurukul Road, Memnagar, Ahmedabad, Gujarat 380052, India Tel: +91 792749 2303/ +9179 2749 0909; Fax: +917927411200

E-mail: icirc@

abhayvasavada.com

Received: 6 August 2013 Accepted in revised form: 3 February 2014 Published online: 28 March 2014
Abstract

Aim To compare the development of posterior capsule opacification ( $\mathrm{PCO}$ ) between eyes with and without diabetes mellitus after single-piece hydrophobic acrylic intraocular lens implantation 4 years postoperatively.

Methods In this prospective, observational case-control study carried out at Iladevi Cataract and IOL Research Centre, Ahmedabad, India, 75 consecutive eyes with diabetes mellitus (cases) were compared with 75 age-matched eyes with age-related cataract (controls). A detailed, preoperative and posterior segment evaluation was carried out in eyes with diabetes mellitus to detect the presence or absence of diabetic retinopathy (DR). The Mann-Whitney $U$-test was applied to compare the differences in the development of PCO between the two groups.

Results There was no difference in median PCO between cases and controls at 1 month (2.0 vs 1.50, $P<0.068$ ), but cases had a higher median PCO at 12 months (2.95 vs 1.30, $P<0.001)$. At 4 years, there was no significant difference in median PCO between cases and controls (3.75 vs 2.25, $P=0.273)$. The duration of diabetes increased the incidence of PCO at 4 years $(P=0.02)$. Severity of DR had no influence on the progress of $\mathrm{PCO}$ at 4 years $(P=0.69)$.

Conclusion Diabetes mellitus did not increase the incidence of PCO at 4 years. The duration of diabetes increased the risk of PCO. The severity of retinopathy did not influence the development of PCO. Eye (2014) 28, 720-727; doi:10.1038/eye.2014.60; published online 28 March 2014
Introduction

Posterior capsule opacification (PCO) is the most frequent long-term complication of phacoemulsification. ${ }^{1,2} \mathrm{PCO}$ is also a frequent and important complication noticed in diabetics undergoing cataract surgery. ${ }^{3-9}$ It has the potential to obscure fundus view, thereby compromising the observation and timely treatment of posterior segment pathologies such as diabetic retinopathy (DR) and macular edema.

After cataract surgery, many surgeons believe that PCO is extensive in diabetic patients compared with non-diabetic patients. ${ }^{7-9}$ However, some studies have reported contradictory results regarding the prevalence of PCO in diabetic $v s$ non-diabetic patients. ${ }^{3-6}$ A few studies have quantitatively evaluated PCO; the results, however, are still controversial. ${ }^{4,8,9}$

There is paucity of available literature that prospectively evaluates the development of PCO with the implantation of a single-piece hydrophobic acrylic intraocular lens (IOL) in diabetic vs non-diabetic eyes on a long-term basis. Therefore, this study was designed to compare the degree of PCO after cataract surgery between age-matched diabetic and nondiabetic patients. In this study, the $\mathrm{POCO}^{10}$ system was used to obtain objective and quantitative measurements for PCO.

\section{Materials and methods}

This prospective, observational case-control study comprised patients who underwent phacoemulsification from June 2005 to June 
2006 at the Iladevi Cataract and IOL Research Center. Informed consent was obtained from all participants, and the ethics committee at Iladevi Cataract and IOL Research Centre reviewed the study. Subjects with a history of diabetes mellitus (DM) were designated as Group A ( $n=75$ eyes). We used the following inclusion criteria for cases: DM was defined as glycosylated hemoglobin $\left(\mathrm{Hb} \mathrm{A}_{1 \mathrm{c}}\right)$ levels of $6 \%$ or more, use of diabetic medication (oral hypoglycemic agents, insulin injection, or diet restriction), or a physician's diagnosis of diabetes. Patients with uncomplicated age-related cataract who were otherwise healthy constituted Group B $(n=75$ eyes). The exclusion criteria were as follows: having glaucoma, high myopia (axial length $>27.0 \mathrm{~mm}$ ), pseudoexfoliation, traumatic cataract, subluxated cataract, previous ocular surgeries, and allergy to dilating drops.

Cataract was categorized as nuclear, cortical, posterior subcapsular, and mixed cataract or a combination of cataracts according to the zone of opacification. After dilating the pupils, the participants were subjected to a slit lamp examination. The slit lamp beam was fixed at a width of $1.0 \mathrm{~mm}$, height of $14.0 \mathrm{~mm}$, and magnification of $8 \mathrm{~mm}$ at $100 \%$ illumination. The fundus examination included direct and indirect ophthalmoscopy. A detailed posterior segment evaluation was carried out in eyes with DM to detect the presence or absence of DR at each scheduled examination. Further, the retinal specialist classified and confirmed the findings. DR was classified according to the early treatment diabetic retinopathy study classification. ${ }^{11}$ A single surgeon (ARV) performed all the surgeries using the Infiniti Vision System (Alcon Laboratories, Fort Worth, TX, USA). A standardized technique was used to ensure comparative consistency in all subjects as described elsewhere. ${ }^{12}$ A single-piece hydrophobic acrylic (model: SN60AT, Alcon Laboratories) IOL was implanted in the capsular bag. Postoperatively, all patients were given 1\% prednisolone acetate eye drops along with $0.3 \%$ Ciprofloxacin eye drops and $1 \%$ Tropicacyl eye drops. Diclofenac sodium eye drops were administered only in diabetic eyes.

\section{Sample size calculation}

Based on published data from a study on adults undergoing phacoemulsification with IOL implantation, the authors observed that at the 1-year follow-up, the mean \pm SD of the POCO value for controls was $16 \pm 16 . .^{13}$ Based on these observations as well as discussions with an expert panel, we assumed that PCO would be $10 \%$ more $(26 \pm 27)$ in Group A than in Group B patients. Using these inputs, we calculated that a sample size of 67 eyes in each group would have more than $80 \%$ power for this study. Allowing for a $10 \%$ dropout rate, we recruited 75 patients in each group.

\section{Observation procedures}

Follow-up examination and image acquisition The patients were asked to return for postoperative follow-up visits at 1 month, 1 year, and 4 years. A masked examiner performed digital retroillumination photo documentation in all patients at the 1-month follow-up, after maximal pupil mydriasis, at a fixed illumination and magnification. For this purpose, we used a digital camera (Nikon/Kodak NC2000e, Nikon Corp., Tokyo, Japan) mounted on a slit lamp (Nikon photo slit-lamp FS-3V) with an external light and flash light sources, which provided coaxial illumination from the flash pack through a fiber optic cable attached to the camera. ${ }^{14}$ At every follow-up visit, thereafter, photo documentation of the posterior capsule was performed using retroillumination with a widely dilated pupil. The eye was considered to have total cover if the non-overlap of the anterior capsule on the IOL optic was equal to or less than 2 clock hours. ${ }^{15}$ The eye was considered to have partial cover if the non-overlap of the anterior capsule on the IOL optic was equal to or greater than 10 clock hours. ${ }^{15}$

\section{PCO image interpretation and analysis All the digital} images were analyzed for PCO using the POCO system. ${ }^{10}$ PCO was assessed by digital retroillumination images of the posterior capsule obtained using a modified Nikon anterior segment slit lamp camera system. Image quality was checked immediately, after which the images were transmitted to St Thomas' Hospital London via the Internet for image analysis using the POCO system. The POCO system is a texturebased analysis of digital photographic images. Results were obtained in percentages of opacification areas and ranged from $0 \%$ to $100 \%$. We defined the area of interest as that part of the posterior capsule lying inside the rhexis or the edge of the lens optic if the rhexis lay off the implant. This area is called the mask. All images then underwent a protocol of processing steps with identical parameters for each image, consisting of removal of the Purkinje light reflexes, contrast enhancement, filtering, and texture segmentation. Finally, the co-occurrence matrix was matched to the raw image and the area of opacification converted to binary to provide the percentage of PCO.

Primary observations: The primary observations were a comparison of the median percentage area of $\mathrm{PCO}$ within the anterior capsulorhexis in Group A and Group B using POCO software (St Thomas Hospital, London, UK). Further, we compared whether the anterior capsule on the IOL optic (total on and part on) had any influence on the 
development of PCO between the two groups. The number of eyes that required Nd:YAG laser capsulotomy was also compared between the two groups.

Secondary observations: On the first postoperative day, anterior segment inflammation was compared between the two groups. Uveal inflammation was graded according to Hogan's criteria. ${ }^{16}$ Anterior capsule opacification (ACO) was also compared at 12 months between the two groups. ACO was evaluated using a slit lamp with oblique illumination at $\times 12$ magnification. ACO was scored in each eye from 0 to 4 , as proposed by Werner and colleagues, ${ }^{17}$ according to the degree/area of capsule opacification. ACO was graded as follows: grade 0 : no opacification, grade 1: only the edge of anterior capsulorhexis opacification, grade 2: diffuse opacification with folds, grade 3 : intense opacification with folds and grade 4: constriction of the capsulorhexis opening.

Within Group A, influence of the duration of diabetes (number of years diabetes was present at the time of surgery) was compared with the development of PCO at 4 years. The influence of the severity of retinopathy on the development of PCO at 4 years was then evaluated. To avoid significant bias, the anterior segment examiners (MRP and GDS), while evaluating for inflammatory markers (flare and cells, and ACO and PCO), were masked as to whether the patients were diabetic or not.

The results were analyzed for best corrected visual acuity, which was recorded in LogMAR units at 1 month, 1 and 4 years postoperatively.

As the data distribution was not normal, as confirmed by the Shapiro-Wilks test for both the groups, nonparametric tests were used to test for differences between the two groups. The Mann-Whitney ' $U$ ' test was applied to compare the differences in the development of PCO and also to assess the influence of the anterior capsule relationship on PCO between the two groups. The relationship between the duration of diabetes and the development of PCO was analyzed using regression analysis. Furthermore, the influence of the severity of retinopathy on the development of PCO was also assessed.

We certify that all applicable institutional and governmental regulations concerning the ethical use of human volunteers were followed during this research.

\section{Results}

The demographic and preoperative characteristics of the study population are given in Table 1 . There were no significant differences in age (Group A vs Group B: $59 \pm 3.1$ vs $61 \pm 2.7$ years, $P=0.63$ ( $t$-test)), gender distribution (Group A vs Group B: male (subjects): $47(62.67 \%)$ vs 42(56\%), $P=0.38$; female (subjects):
$28(37.33 \%)$ vs 33(44\%), $P=0.38$ ( $P$-value of test of proportion)), axial length (Group A vs Group B: $23.88 \pm 1.49$ vs $23.47 \pm 1.11 \mathrm{~mm}, P=0.16$ ( $P$-value of Mann-Whitney test)), and different types of cataract (Group A vs Group B: ( $n=$ eyes) nuclear cataract: 12(16.0\%) vs19(25.3\%), $P=0.17$; cortical cataract: $3(4.0 \%)$ vs $3(4.0 \%), P=1.0$; posterior subcapsular cataract: $2(2.7 \%)$ vs $1(1.3 \%), P=0.33$; mixed cataract: $58(77.3 \%)$ vs $52(69.3 \%), P=0.54$ ( $P$-value of test of proportion)) between the two groups. There was no difference in the mean postoperative follow-up between the two groups $(48.0 \pm 3.6$ and $48.0 \pm 3.1$ months $)(P=0.42)$.

\section{Primary observations}

Median POCO values in cases and controls There was no difference in $\mathrm{POCO}$ values of the median percentage area in Group A and Group B at 1 month (2.0 vs 1.50, $P=0.068$ ). However, at 12 months, Group A had a higher POCO value of the median percentage area as compared with Group B (2.95 vs 1.30, P<0.001). At the 4-years follow-up, there was no significant difference in POCO values of the median percentage area between Group A and Group B (3.75 vs 2.25, $P=0.273$ ) (Table 1).

Median POCO values with the anterior capsule relationship (total on and part on): There were equal numbers of eyes with total on (Group A vs Group B: 53 (70.7\%) eyes vs $49(65.3 \%)$ eyes, $P=0.43$ ) and part on (Group A vs Group B: $22(29.3 \%)$ eyes vs $26(34.6 \%)$ eyes, $P=0.59)$ between Groups A and B, with no statistically significant difference. In both Groups A and B, the influence of the anterior capsule cover (total on and part on) on the development of PCO was also analyzed. In the group with total anterior capsule overlap on the IOL optic, at the 1-month $(P=0.008)$ and 1 -year $(P=0.006)$ follow-up, the POCO values of the median percentage area were significantly higher in Group A compared with Group B. However, at 4 years, there was no statistically significant difference between Group A and Group B $(P=0.592)$ (Figure 1 and Table 2).

In the group with partial anterior capsule overlap on the IOL optic, at the 1 -month $(P=0.450)$ and 4-years $(P=0.170)$ follow-up, there was no significant difference in POCO values of the median percentage area between Group A and Group B. However, at 1 year, there was a statistically significant difference between Group A and Group B $(P=0.008)$ (Figure 2 and Table 2).

Further, in the present study we observed that within Group A and Group B eyes with partial anterior capsule overlap on the IOL optic had a greater development of PCO at 1 and 4 years, with a significant difference in the POCO values of the median percentage area when compared with eyes with total anterior capsule overlap 
on the IOL optic (Group A: 1 month $(P=0.83), 1$ year $(P=0.03)$, and 4 years $(P=0.01)$; Group B: 1 month $(P=0.12), 1$ year $(P=0.03)$, and 4 years $(P=0.01)$

(Table 3))

Nd:YAG capsulotomy rates Two eyes $(2.66 \%)$ in each group underwent Nd:YAG capsulotomy.

\section{Secondary observations}

Anterior segment inflammation There was no statistically significant difference in the influence of the anterior

Table 1 Comparison of patient demographics between eyes with diabetes mellitus (Group A) and eyes without diabetes mellitus (Group B)

\begin{tabular}{lccc}
\hline & $\begin{array}{c}\text { Diabetes } \\
\text { mellitus } \\
\text { Group A }\end{array}$ & $\begin{array}{c}\text { No diabetes } \\
\text { mellitus } \\
\text { Group B }\end{array}$ & P-value \\
\hline Age (years) & $59 \pm 3.1$ & $61 \pm 2.7$ & 0.63 \\
Axial length (mm) & $23.88 \pm 1.49$ & $23.47 \pm 1.11$ & 0.16 \\
Gender & & & \\
$\quad$ Male & $47(62.67 \%)$ & $42(56 \%)$ & 0.38 \\
Female & $28(37.33 \%)$ & $33(44 \%)$ & \\
Type of cataract & & & \\
Nuclear & $12(16.0 \%)$ & $19(25.3 \%)$ & 0.17 \\
Cortical & $3(4.0 \%)$ & $3(4.0 \%)$ & 1.00 \\
Posterior subcapsular & $2(2.7 \%)$ & $1(1.3 \%)$ & 0.33 \\
Mixed & $58(77.3 \%)$ & $52(69.3 \%)$ & 0.54 \\
\hline
\end{tabular}

Age: $P$-value of $t$-test.

Axial length: $P$-value of Mann-Whitney test.

Gender: $P$-value of test of proportion.

Type of cataract: $P$-value of test of proportion chamber flare (Group A vs Group B: ' <2' 37 (49.3\%) eyes vs $42(56 \%)$ eyes, $P=0.51 ;$ ' $>2 / 2^{+'}$ : $38(50.6 \%)$ vs 33 (44\%), $P=0.51$ ( $P$-value of Fisher's exact test)) and anterior chamber cells (Group A vs Group B: ' $<2$ ': 37 (49.3\%) eyes vs 36 (48\%) eyes, $P=0.99 ;$ ' $>2 / 2^{+'}$ : $38(50.6 \%)$ eyes vs 39(52\%) eyes, $P=0.99$ ( $P$-value of Fisher's exact test)) between the two groups on the first postoperative day.

Anterior capsule opacification (ACO) There was no statistically significant difference in the influence of ACO between the two groups at 12 months postoperatively (Grade 1: Group A vs Group B: 11(14.6\%) eyes vs 12(16\%) eyes, $P=0.87$, Grade 2: Group A vs Group B: $51(68 \%)$ eyes vs 53(70.6\%) eyes, $P=0.69$, Grade 3: Group A vs Group B: $13(17.3 \%)$ eyes vs $10(13.3 \%)$ eyes, $P=0.49$ ( $P$-value: test of proportion)). None of the eyes in both the groups developed 4 degrees of ACO.

Duration of diabetes and PCO Regression was attempted using PCO at 4 years as a dependent variable and the duration of diabetes at the time of surgery as an independent variable. It was observed that each time the duration of diabetes increased by a year there was, on an average, a $1 \%$ rise in $\mathrm{PCO}$ attaining statistical significance (Any increase in the duration of diabetes increases the odds of developing PCO by $1 \%)(P=0.023)$.

Severity of retinopathy and PCO Although there was an increase in mean PCO at 4 years across different grades of severity of retinopathy, the grades of severity of retinopathy did not have any significant influence on the
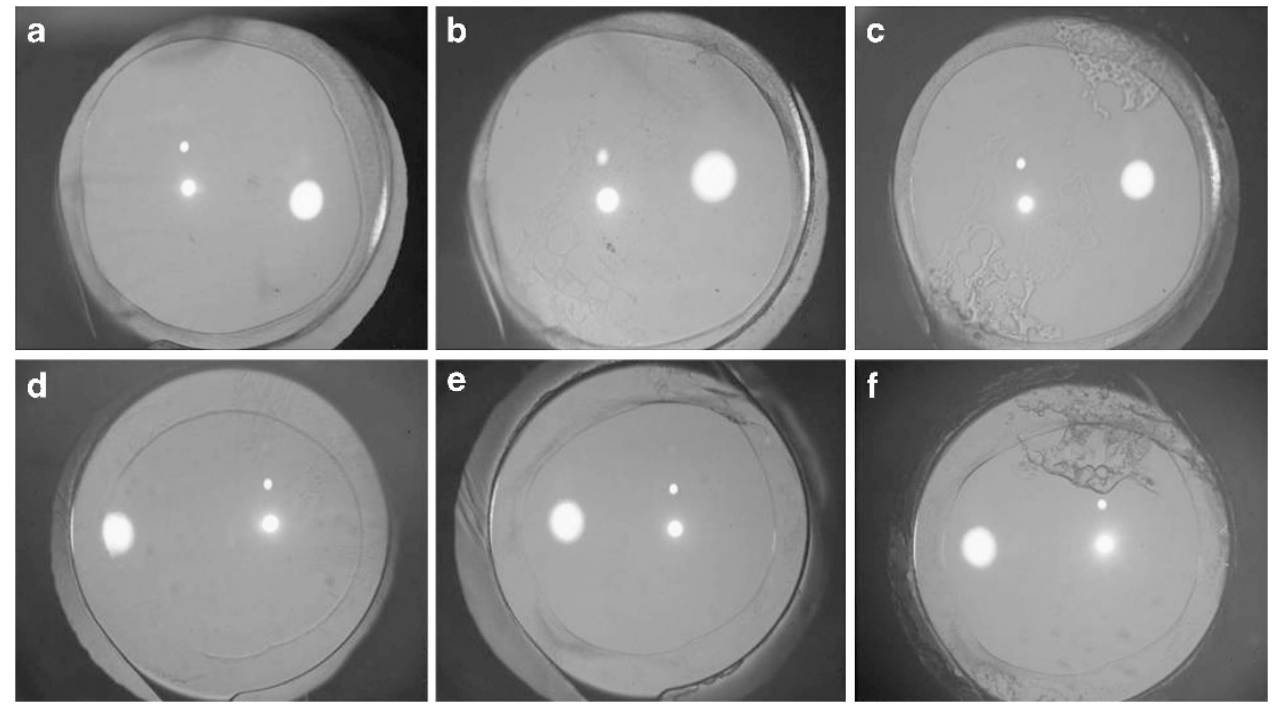

Figure 1 A comparative evaluation of postoperative posterior capsule opacification in the total on group, between diabetes mellitus (Group A) (a-c) and no diabetes mellitus (Group B) (d-f) at 1 month, 1 year, and 4 years, respectively. 
development of PCO (mean PCO: 1 year: $6.2 \%$; 2 years: $6.6 \%$; 3 years: $12.7 \%$; 4 years: $20.3 \%, P=0.69$ ) (Figure 3 )

Visual acuity There was no statistically significant difference in the BCVA between the two groups postoperatively at 1 month (Group A vs Group B: mean LogMAR: $0.19 \pm 0.13$ vs $0.18 \pm 0.07, P=0.96), 1$ year (Group A vs Group B: mean LogMAR: $0.15 \pm 0.11$ vs $0.18 \pm 0.11, P=0.13$ ), and 4 years (Group A vs Group B: mean LogMAR: $0.18 \pm 0.19$ vs $0.16 \pm 0.17, P=0.72$ (P-value: Mann-Whitney test)).

\section{Discussion}

Our study has demonstrated that both diabetic and nondiabetic patients developed a similar degree of PCO after cataract surgery at the 4-years follow-up. Using the POCO method, for up to 12 months after surgery, we noted a higher degree of PCO in diabetic patients compared with non-diabetic patients. These results

Table 2 Comparison of the development of PCO within the capsulorhexis margin between eyes with diabetes mellitus (Group A) and eyes without diabetes mellitus (Group B)

\begin{tabular}{lccccc}
\hline & $\begin{array}{c}\mathrm{N} \\
\text { (eyes) }\end{array}$ & $\begin{array}{c}\text { Diabetes } \\
\text { mellitus } \\
\text { Group A }\end{array}$ & $\begin{array}{c}\mathrm{N} \\
\text { (eyes) }\end{array}$ & $\begin{array}{c}\text { No diabetes } \\
\text { mellitus } \\
\text { Group B }\end{array}$ & \\
\hline 1 Month & 75 & 2.00 & 75 & 1.50 & 0.068 \\
1 Year & 72 & 2.95 & 70 & 1.30 & 0.001 \\
4 Years & 70 & 3.75 & 68 & 2.25 & 0.273 \\
\hline
\end{tabular}

Abbreviation: $N$ (eyes), number of eyes.

${ }^{*} P$-value of Mann-Whitney test. indicate that PCO in diabetic patients progressed only in the early postoperative period. The incidence of PCO in diabetics has been a controversial subject in literature. Hayashi et $a l^{8}$ reported no significant difference between the two groups for up to 1 year after surgery. However, at 3 years, $\mathrm{PCO}$ in diabetics was significantly greater than in the controls. Nekolova et $a l^{6}$ reported no significant difference in the extent of PCO development or in the rate of Nd:YAG capsulotomy at 7 years. Conversely, Elgohary et $a l^{5}$ reported that diabetes appears to be

Table 3 Comparison of the development of posterior capsule opacification between eyes with 'part on' and 'total on' overlap of the anterior capsule between eyes with diabetes mellitus (Group A) and eyes without diabetes mellitus (Group B)

\begin{tabular}{|c|c|c|c|c|}
\hline & $\begin{array}{c}\text { Capsule } \\
\text { cover }\end{array}$ & $\begin{array}{c}\mathrm{N} \\
\text { (eyes) }\end{array}$ & $\begin{array}{c}\text { Median } \\
(\%)\end{array}$ & *P-value \\
\hline \multicolumn{5}{|c|}{ Diabetes mellitus (Group A) } \\
\hline \multirow[t]{2}{*}{1 Month } & Part On & 22 & 2.10 & 0.83 \\
\hline & Total On & 53 & 1.90 & \\
\hline \multirow[t]{2}{*}{1 Year } & Part On & 22 & 5.20 & 0.03 \\
\hline & Total On & 50 & 2.65 & \\
\hline \multirow[t]{2}{*}{4 Years } & Part On & 21 & 8.00 & 0.01 \\
\hline & Total On & 49 & 2.60 & \\
\hline \multicolumn{5}{|c|}{ No diabetes mellitus (Group B) } \\
\hline \multirow[t]{2}{*}{1 Month } & Part On & 25 & 2.35 & 0.12 \\
\hline & Total on & 50 & 1.50 & \\
\hline \multirow[t]{2}{*}{1 Year } & Part On & 23 & 2.75 & 0.03 \\
\hline & Total On & 47 & 1.80 & \\
\hline \multirow[t]{2}{*}{4 Years } & Part On & 22 & 6.40 & 0.01 \\
\hline & Total On & 46 & 2.10 & \\
\hline
\end{tabular}

Abbreviation: $N$ (eyes), number of eyes. ${ }^{*} P$-value of Mann-Whitney test.

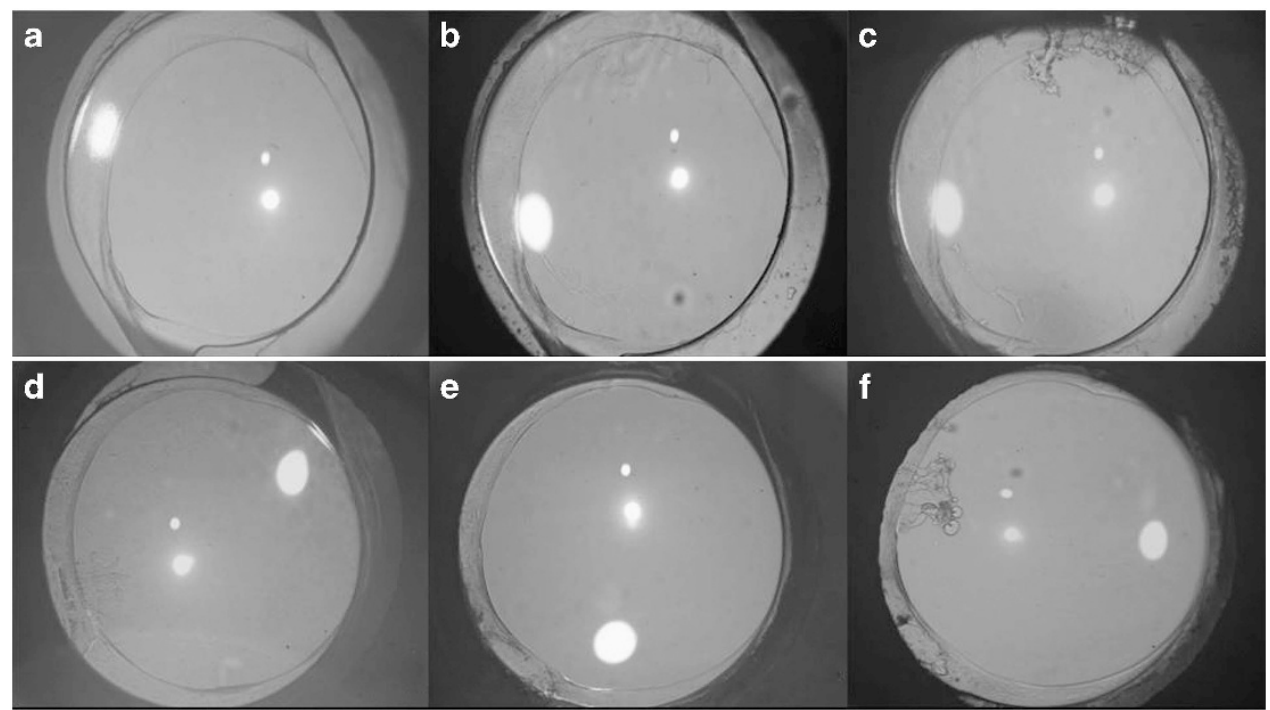

Figure 2 A comparative evaluation of postoperative images of posterior capsule opacification in the part on group between diabetes mellitus (Group A) (a-c) and no diabetes mellitus (Group B) (d-f) at 1 month, 1 year, and 4 years, respectively. 


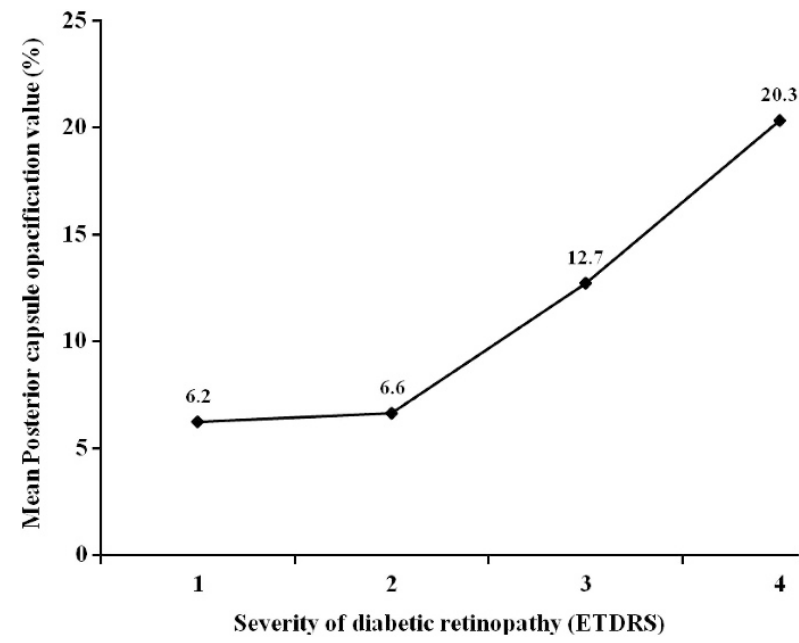

Figure 3 The distribution of mean posterior capsule opacification at 4 years postoperatively across different grades of severity of diabetic retinopathy in eyes undergoing phacoemulsification.

associated with a lower incidence and a decreased risk of YAG capsulotomy at 4 years. Zaczek et $a l^{4}$ reported similar findings at 2 years. Knorz et $a l^{3}$ stated that the low incidence of PCO in diabetics was due to the accumulation of sorbitol and fructose in the lens epithelial cells, which they believed contributed to PCO development. These contradictions in earlier results can be explained by the differences in age groups of the study population, surgical techniques used,

postoperative follow-up periods, the IOL materials used, and mostly by the differences in the quantitative measurement of PCO. We believe that the low incidence of postoperative $\mathrm{PCO}$ in our series could be attributed to various factors such as the different profiles of our diabetic patients in terms of duration and severity of diabetes, refinements in surgical techniques, the presence of a total overlap on the IOL optic, and the implantation of a single-piece hydrophobic acrylic IOL. Based on the observations made in the present study, we believe that, in the total on subgroup in Group B, the decrease in POCO values from 1 month to 1 year could probably be attributed to the fact that at 1 month there may have been some residual cortical fibers, which may have regressed by 1 year. The same also applies to the part on subgroup in Group B, especially given the fact that the development of PCO is a dynamic process. In the present study, we observed lower PCO rates. It is possible that administering prophylactic treatment for postoperative inflammation reduced the development of PCO. In experimental studies, it has been suggested that use of steroids and diclofenac sodium causes an inhibitory effect on LEC proliferation and extracellular matrix formation. ${ }^{18,19} \mathrm{~A}$ few reports have suggested that the lower PCO rate in diabetic patients could be attributed to the decreased density of LECs in the diabetic capsular bag. ${ }^{20}$

In the present study, we did not find significant differences in the incidence of cells and flare on the first postoperative day. It is well known that eyes of diabetic patients have pre-existing deterioration of the blood aqueous barrier function are more predisposed to barrier damage associated with surgical invasion. ${ }^{21-24} \mathrm{~A}$ few reports found increased flare intensity in patients with DM. ${ }^{21,24}$ Further, in the same study the authors observed increased anterior segment flare parallel with advancing stages of DR. ${ }^{24}$ In one of the studies, the authors reported that the highest flare intensity after cataract surgery was in eyes with advanced stages of DR and with clinically significant macular edema. ${ }^{24}$

ACO generally occurs much earlier than PCO and may occur as early as a month after surgery. ${ }^{25-27}$ It has been shown that the anterior capsule opening shrinks rapidly during the first month after cataract surgery and IOL implantation, followed by a slower progressive reduction in the next 6 months. ${ }^{25-27}$ Therefore, we decided to evaluate ACO up to 1 year postoperatively. In the present study, we did not find significant differences in the severity of ACO at 1 year postoperatively. We speculate that anterior capsule contraction may depend on the initial size of the capsulorhexis. We further believe that performing a larger capsulorhexis may avoid contraction of the anterior capsule and help in facilitating fundus visualization and management of retinal pathologies in diabetic patients. In the present study, we did not measure the initial size of the capsulorhexis postoperatively and the overall changes in the capsulorhexis size over a period of time during the entire follow-up period, as it was not our primary observation. In another study, the authors found no significant correlation between the degree of contraction of the anterior capsule opening and the severity of PCO in patients with DM..$^{28}$ In the present study, we did not find significant differences in the incidence of Nd:YAG laser capsulotomy between the two groups. Another factor, which we had to keep in mind, was the conservative approach of surgeons coupled with the mindset of people in this part of the world who prefer to avoid surgical intervention unless it is absolutely warranted. Hence Nd:YAG capsulotomy was performed only when the patient requested it.

Given these facts, we believe that the incidence of Nd:YAG capsulotomy may not be an accurate indicator of the development of PCO. A few authors ${ }^{6}$ found no significant difference in Nd:YAG capsulotomy rates and operative Elschnigg pearls removal. The contradictions in the results of these studies could be attributed to the differences in the clinical features of these patients, techniques employed, or the duration of follow-up. 
In the present study, an increase in mean PCO was found at 4 years across different levels of severity of retinopathy. However, these differences did not achieve statistical significance over the grades of severity of retinopathy. In another study, the authors ${ }^{7}$ found a higher incidence of PCO in diabetics with nonproliferative or quiescent proliferative retinopathy than in diabetics without retinopathy, but this was not statistically significant. We believe that since the blood aqueous barrier breakdown is more severe in eyes with advanced retinopathy, chemical mediators that stimulate proliferation of LECs must be present abundantly in eyes with advanced DR, which may subsequently lead to extensive PCO.

Moreover, in the present study, regression analysis suggested a strong association between duration of diabetes and PCO. However, a few authors ${ }^{8}$ suggested that the systemic condition of diabetics and even the duration of diabetes at the time of surgery might not be proportional to the development of PCO. In another study, the authors suggested that in diabetic patients there was no association between the type of diabetes, the duration or retinopathy, and the grade and risk of Nd:YAG capsulotomy. ${ }^{5}$

The present study emphasizes our notion that when partial anterior capsule overlap is compared between Groups A and B there is no significant difference in the risk of the development of PCO after implantation of the single-piece AcrySof IOL. We observed that complete anterior capsule overlap was not a contributing factor towards the development of PCO after three-piece AcrySof IOL implantation. ${ }^{15}$ We chose a single-piece hydrophobic acrylic IOLfor implantation. Literature reports suggest that this material is associated with a lower degree of PCO formation. ${ }^{29,30}$ A few authors ${ }^{31}$ found that in patients older than 60 years the rate of $\mathrm{PCO}$ formation was significantly lower in patients with DM and with an acrylic PC IOL than in patients without DM with a silicone foldable PC IOL. In contrast, within groups $\mathrm{A}$ and $\mathrm{B}$, in eyes with partial anterior capsule overlap on the IOL optic there was a higher level of development of PCO, with a significant difference when compared with eyes with total anterior capsule overlap on the IOL optic. From the above observations and literature, it is well established that partial non-overlap of the anterior capsule on the IOL optic results in an incomplete capsule bend formation, thereby causing a gap between the IOL optic and the posterior capsule. This gap provides a channel for the lens epithelial cells to migrate onto the posterior capsule, causing extensive PCO.

The limitation of the present study is that we did not compare the systemic status of diabetes in terms of blood glucose level with the development of PCO and opacification of the peripheral posterior capsule between the two groups. The other limitation of the present study is not using a fixed area within the pupil to measure PCO. The last limitation is we have not compared the low contrast sensitivity between two groups, which would have been interesting to clinicians and the patients. This study aimed at prospectively exploring the long-term effect of diabetes on the incidence of PCO. It was important for us to implement standardized surgical techniques for in-the-bag AcrySof IOL fixation and postoperative medication so as to ensure that the surgeries were as identical as possible for both groups. This kind of standardization helped us to objectively evaluate whether diabetic patients run the risk of developing PCO. In conclusion, our study has shown that at the end of 4 years the presence of diabetes mellitus did not increase the risk of development of PCO when compared with non-diabetic patients. Furthermore, the severity of DR did not influence the development of PCO in diabetics. However, the duration for which diabetes was present in the eye had a definite impact on PCO development in these patients.

\section{Summary}

What was known before

- After cataract surgery, many surgeons believe that PCO is extensive in diabetic patients as compared with nondiabetic patients.

- However, some studies have reported contradictory results regarding the prevalence of PCO in diabetics.

What this study adds

- Our study has shown that at the end of 4 years the presence of diabetes mellitus did not increase the risk of development of PCO when compared with non-diabetic patients.

\section{Conflict of interest}

The authors declare no conflict of interest.

\section{Acknowledgements}

The Iladevi Cataract \& IOL Research Centre received research support for travel to meetings for the study from Alcon Laboratories, Fort Worth, USA.

\section{References}

1 Apple DJ, Solomon KD, Tetz MR, Assia EI, Holland EY, Legler UF et al. Posterior capsule opacification. Surv Ophthalmol 1992; 37: 73-116.

2 Sterling S, Wood TO. Effect of intraocular lens convexity on posterior capsule opacification. J Cataract Refract Surg 1986; 12: 655-657. 
3 Knorz MC, Soltau JB, Seiberth V, Lorger C. Incidence of posterior capsule opacification after extracapsular cataract extraction in diabetic patients. Metab Pediatr Syst Ophthalmol 1991; 14: 57-58.

4 Zaczek A, Zetterstrom C. Posterior capsule opacification after phacoemulsification in patients with diabetes mellitus. J Cataract Refract Surg 1999; 25: 233-237.

5 Elgohary MA, Dowler JG. Incidence and risk factors of Nd:YAG capsulotomy after phacoemulsification in non-diabetic and diabetic patients. Clin Exp Ophthalmol 2006; 34: 526-534.

6 Nekolová J, Pozlerová J, Jirásková N, Rozsíval P. Posterior capsule opacification in patients with type 2 diabetes mellitus. Cesk Slov Oftalmol 2008; 64: 193-196.

7 Ionides A, Dowler JG, Hykin PG, Rosen PH, Hamilton AM. Posterior capsule opacification following diabetic extracapsular cataract extraction. Eye (Lond) 1994; 8(Pt 5): 535-537.

8 Hayashi K, Hayashi H, Nakao F, Hayashi F. Posterior capsule opacification after cataract surgery in patients with diabetes mellitus. Am J Ophthalmol 2002; 134: 10-16.

9 Ebihara Y, Kato S, Oshika T, Yoshizaki M, Sugita G. Posterior capsule opacification after cataract surgery in patients with diabetes mellitus. J Cataract Refract Surg 2006; 32: 1184-1187.

10 Barman SA, Hollick EJ, Boyce JF, Spalton DJ, Uyyanonvara B, Sanguinetti G et al. Quantification of posterior capsular opacification in digital images after cataract surgery. Invest Ophthalmol Vis Sci 2000; 41: 3882-3892.

11 Lang GE. Laser treatment of diabetic retinopathy. Lang GE (ed.) Diabetic Retinopathy, Vol. 39. Karger: Basel, 2007, pp 48-68.

12 Vasavada AR, Raj S. Step-down technique. J Cataract Refract Surg 2003; 29: 1077-1079.

13 Bender LE, Nimsgern C, Jose R, Jayaram H, Spalton DJ, Tetz MR et al. Effect of 1-piece and 3-piece AcrySof intraocular lenses on the development of posterior capsule opacification after cataract surgery. J Cataract Refract Surg 2004; 30: 786-789.

14 Shah AR, Praveen MR, Vasavada AR. Posterior capsule opacification after extra capsular cataract extraction in Indian rural population: foldable acrylic vs poly (methylmethacrylate) intraocular lenses a randomized clinical trial. Eye (Lond) 2008; 22: 889-894.

15 Vasavada AR, Raj SM. Anterior capsule relationship of the AcrySof intraocular lens optic and posterior capsule opacification: a prospective randomized clinical trial. Ophthalmology 2004; 111: 886-894.

16 Uveitis Kanski JJ. Clinical Ophthalmology: A Systematic Approach. 3rd edn. Butterworth-Heinemann: Oxford, 1994, pp 152-153.

17 Werner L, Pandey SK, Apple DJ, Escobar-Gomez M, McLendon L, Macky TA. Anterior capsule opacification: correlation of pathologic findings with clinical sequelae. Ophthalmology 2001; 108: 1675-1681.

18 Mansfield KJ, Cerra A, Chamberlain CG. Effects of dexamethasone on posterior capsule opacification-like changes in a rat lens explant model. Mol Vis 2004; 6 : 728-737.

19 Cortina P, Gómez-Lechón MJ, Navea A, Menezo JL, Terencio MC, Diaz-Llopis M. Diclofenac sodium and cyclosporine A inhibit human lens epithelial cell proliferation in culture. Graefes Arch Clin Exp Ophthalmol 1997; 235: 180-185.

20 Saitoh J, Nishi O, Hitani H. Cell density and hexagonality of lens epithelium in human cataracts. Nippon Ganka Gakkai Zasshi 1990; 94: 176-180.

21 Moriarty AP, Spalton DJ, Moriarty BJ, Shilling JS, Ffytche TJ, Bulsara M. Studies of the blood-aqueous barrier in diabetes mellitus. Am J Ophthalmol 1994; 117: 768-771.

22 Oshika T, Kato S, Funatsu H. Quantitative assessment of aqueous flare intensity in diabetes. Graefes Arch Clin Exp Ophthalmol 1989; 227: 518-520.

23 Ino-ue M, Azumi A, Shirabe H, Tsukahara Y, Yamamoto M. Laser flare intensity in diabetics: correlation with retinopathy and aqueous protein concentration. Br J Ophthalmol 1994; 78: 694-697.

24 Zaczek A, Zetterstrom C. Aqueous flare intensity after phacoemulsification in patients with diabetes mellitus. J Cataract Refract Surg 1998; 24: 1099-1104.

25 Hayashi K, Hayashi H, Nakao F, Hayashi F. Reduction in the area of the anterior capsule opening after polymethylmethacrylate, silicone, and soft acrylic intraocular lens implantation. Am J Ophthalmol 1997; 123: 441-447.

26 Hara T, Azuma N, Chiba K, Ueda Y, Hara T. Anterior capsular opacification after endocapsular cataract surgery. Ophthalmic Surg 1992; 23: 94-98.

27 Hansen SO, Crandall AS, Olson RJ. Progressive constriction of the anterior capsular opening following intact capsulorhexis. J Cataract Refract Surg 1993; 19: 77-82.

28 Hayashi Y, Kato S, Fukushima H, Numaga J, Kaiya T, Tamaki Y et al. Relationship between anterior capsule contraction and posterior capsule opacification after cataract surgery in patients with diabetes mellitus. J Cataract Refract Surg 2004; 30: 1517-1520.

29 Linnola RJ, Werner L, Pandey SK, Escobar-Gomez M, Znoiko SL, Apple DJ. Adhesion of fibronectin, vitronectin, laminin, and collagen type IV to intraocular lens materials in pseudophakic human autopsy eyes. Part 2: explanted intraocular lenses. J Cataract Refract Surg 2000; 26: 1807-1818.

30 Linnola RJ, Werner L, Pandey SK, Escobar-Gomez M, Znoiko SL, Apple DJ. Adhesion of fibronectin, vitronectin, laminin, and collagen type IV to intraocular lens materials in pseudophakic human autopsy eyes. Part 1: histological sections. J Cataract Refract Surg 2000; 26: 1792-1806.

31 Kim NJ, Lee JH. Effect of an acrylic posterior chamber intraocular lens on posterior capsule opacification in cataract patients with associated risk factors. J Cataract Refract Surg 2003; 29: 1575-1578. 